\title{
Simulated Day and Night Effects on Perceived Motion in an Aircraft Taxiing Simulator
}

\author{
Daniel C. Zikovitz, Keith K. Niall, Laurence R. Harris and Michael Jenkin \\ CAE-Professional Services, Ottawa, Canada [1] \\ Defence Research \& Development Canada Toronto [2] \\ York University, Toronto, Canada [3,4] \\ dzikovitz@cae.com, keith.niall@drdc-rddc.gc.ca,harris@yorku.ca, \\ jenkin@cse.yorku.ca
}

\begin{abstract}
Flight simulation often depends on both visual simulation and movement by a motion base. The present study asks if tilt is equivalently perceived as linear translation, and if so, whether other information such as simulated day or night conditions may affect accuracy. We examine the perception of self-motion in non-pilots during passive simulated airplane taxiing along a straight runway. Providing physical motion cueing by a motion platform, simulation scenarios were presented at a constant physical or visual acceleration of either $0.4 \mathrm{~m} / \mathrm{s}^{2}$ or $1.6 \mathrm{~m} / \mathrm{s}^{2}$ (simulated using tilt). Nine subjects indicated the moment when they perceived that they had travelled through distances between 10 to $90 \mathrm{~m}$ under either day or night-time display conditions. Their estimates were made either with or without tilt (to simulate linear acceleration). We present results as a ratio of response distance (response distance) to stimulus distance (stimulus distance). Subjects' motion estimates under tilt conditions do not significantly differ from under vision-only conditions. We found an interaction of tilt and illumination conditions, particularly for targets greater than $30 \mathrm{~m}$. The ratio of response distance to stimulus distance significantly increases in the dark (1.1 vs. 0.85), at higher accelerations (1.01 for $1.6 \mathrm{~m} / \mathrm{s}^{2}$ vs. 0.95 for $0.4 \mathrm{~m} / \mathrm{s}^{2}$ ) and, during daytime illumination, in the presence of a physical-motion cue (0.92 vs. 0.78$)$.

Conditions affecting the magnitude of perceived self-motion include:

- $\quad$ illumination

- $\quad$ magnitude of the simulated acceleration

- $\quad$ presence of physical tilt during daytime illumination
\end{abstract}

This study shows that passive humans can be expected to make significant, predictable errors in judging taxiing distances under specific simulation conditions. Questions for further research include:

- $\quad$ if similar effects occur in pilots as in non-pilots

- $\quad$ if such effects also occur in real taxiing scenarios

The results obtained here may help to counter perceptual errors, as the results become part of the knowledge on which appropriate cueing schemes can be based. 


\section{Introduction}

Although aircraft taxiing initially appears the least demanding and least dangerous part of air travel, it requires the pilot to use sensory cues in judging the aircraft's motion, unlike flight, which predominantly uses instruments and computer control. Pilot misperception of self-motion during taxiing has led to an increasing number of runway incursions since 2000, as reported by Transport Canada [1]. Small errors in position judgment during aircraft taxiing can lead to accidents. Fotos' [3] report of the following accident in Aviation Week \& Space Technology, is illustrative: “On 3 December 1990; Northwest DC9-14; Detroit, MI: a DC9 was taxiing in fog and strayed onto an active runway where it was hit by a departing Northwest 727. One of the four crew members and seven of the 40 passengers were killed." As shown by this example, misperceptions of self-motion can prove fatal.

Sensory input such as vision, the vestibular apparatus and other proprioceptive information transduce self-motion information in providing an estimate of self-motion. How do humans integrate these cues in perceiving their self-motion? Which cues are critical to the accurate perception of self-motion? We examine these issues in the domain of passive aircraft taxiing. A better understanding of the factors that affect the perception of self-motion while taxiing provides the opportunity for more effective pilot training and the development of measures for countering errors in self-motion perception.

What factors affect pilots' judgements of their travel on the ground? We begin with a simple case: do taxiing subjects accurately perceive how far they have travelled in a straight line along the ground? In maximizing flight-simulation training accuracy, the pilot's self-motion perception in the simulator should match the self-motion perception in the vehicle being simulated as closely as possible. Many current vehicle simulators incorporate visual systems displaying detailed scenes over a wide field of view. Visual stimulation should work well for simulations of constant velocity and simulations below vestibular threshold because the vestibular system is normally inactive under these conditions. However, many vehicle operations involve acceleration, e.g., abrupt changes in direction, altitude or air speed, with accompanying simulation of acceleration; providing this input to the pilot may be important for training. Although these issues are important in simulating motion, low accelerations and extreme distances to objects in the visual field reduce the effectiveness of most sensory cues to motion perception during steady flight. This cueing is most important during ground manoeuvres (e.g., taxiing), with nearby objects and short accelerations providing significant sensory cues to motion as in other ground vehicle simulation, see Vos et al. [4]. Flight simulation with accompanying physical-motion cues is not necessarily perceived as veridical, as shown by Groen and Hosman [5] and Harris et al. [2]. Typical motion-based simulators have a short physical throw distance; sustaining linear acceleration is impossible. Motion simulators attempting to achieve the same perceptual effect as the physical motion of an aircraft must use other methods. One common approach to achieve this simulation is to use the physical tilt of the simulator to simulate linear acceleration. According to Einstein's Equivalence Principle [6], inertial accelerations during translation are physically indistinguishable from gravitational accelerations from tilt. When a component of gravity parallels the otolith macula, distinguishing this component from a comparable linear acceleration due to motion becomes impossible. The equivalence can be exploited by tilting a person, activating the otoliths and simulating linear acceleration. Although a static tilt can simulate forward acceleration, the tilting process also stimulates the semicircular canals. To avoid the sensation of tilting and have the resulting motion perceived as linear motion, the 
rate of tilt applied should be below the canal's detection threshold, reported as $0.5^{\circ} / \mathrm{s} 2$ by Benson et al. [7].

The present study investigates the perceived magnitude of self-motion as forward motion is simulated during taxiing. This simulation was effected by tilting subjects at a rate below the threshold level of the semicircular canals and by determining the effectiveness of this tilting technique and the resulting angular displacement on night-time and daytime simulations. One goal of this work is to determine the relative weighting of visual and physical motion provided in motion-based simulators. A further goal is to lay the groundwork for the development of training techniques for, and countermeasures to, perceptual inaccuracies that can lead to disastrous errors while taxiing. The hypothesis is that tilt significantly increases the perceived magnitude of self-motion perception, while additional factors such as changing from day to night and changing the simulated acceleration level (i.e., changing the angle of tilt) may reduce the effects of tilt.

\section{Methods}

\section{Subjects}

Twelve healthy male volunteers from the ages of 18 to 32 years were recruited from York University. Subjects had normal or corrected-to-normal vision. None of the subjects had pilot training or reported a history of vestibular dysfunction. Subjects were told to signal the operator if they experienced any symptoms of simulator sickness, but no subject asked to stop the experiment for any reason. Subjects read and signed York University and DRDC consent forms and were paid for their participation at standard subject rates. The York University Ethics Committee and DRDC Toronto Human Research Ethics Committee approved the experimental protocols.

\section{Apparatus}

As shown Figure 1, a Jet Ranger ${ }^{\circledR}$ helicopter cockpit mounted on a MotionBase Max Cue, electrically-driven motion platform was used. Translational movement of up to $0.47 \mathrm{~m}$ and rotational movement of up to $45^{\circ}$ yaw and $34^{\circ}$ pitch could be achieved with the platform, although this study only pitched subjects $9.4^{\circ}$, producing a constant acceleration of $1.6 \mathrm{~m} / \mathrm{s}^{2}$ and $2.3^{\circ}$, simulating $0.4 \mathrm{~m} / \mathrm{s}^{2}$ movement. A joystick with a response button was located in the cockpit. An emergency button for subjects to stop the experiment was also located in the cockpit. This button was not used by any of the subjects. 

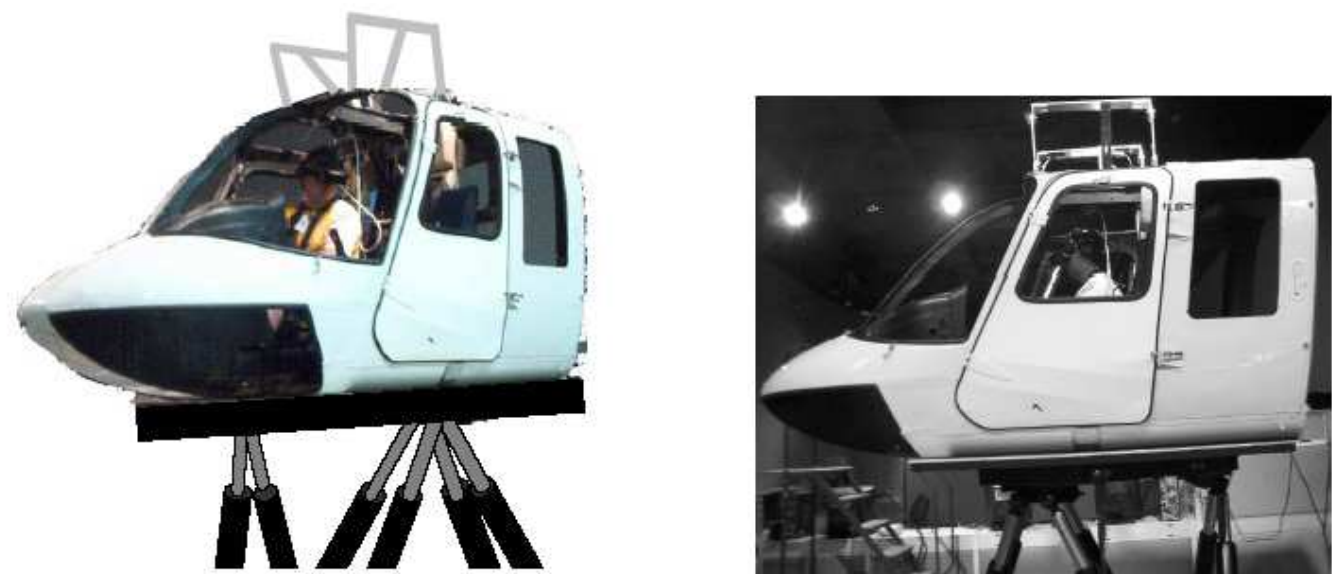

Fig. 1. Front and side views of the simulator used in this study.

Subjects wore a head-tracked Virtual Research V8 stereo head-mounted display (HMD) in binocular mode driven by a Silicon Graphics Inc. (SGI) ${ }^{\circledR}$ computer. The HMD provided a $60^{\circ}$ diagonal field of view at an optical distance of $7 \mathrm{~m}$. Providing $6^{\circ}$ of freedom, user headtracking was provided by an Ascension laserBIRD 2TM head-tracker (accurate within 0.77 $\mathrm{mm})$, updating the visual display based on the subject's head position.

\section{Visual simulation}

Even though the Jet Ranger ${ }^{\circledR}$ cab was used, the simulator was configured to create a visual simulation of the view seen from the cockpit of a HerculesTM aircraft. A crude representation of the instrument panel was displayed below the simulated window; subjects viewed a $780-\mathrm{m}$-long runway of 54-m width through the window. Subjects could explore the cabin visually and look out of any of the forward- and side-facing windows, illustrated in Figures 2 and 3 , before the trial began. A white cross with a horizontal red line running perpendicular to the fore-aft line was shown on the floor of the simulated aircraft. Subjects were instructed to notice this line because it was their reference for distance judgment. Subjects were, however, instructed not to move their heads during the trials.

The visual display simulated either night-time conditions with low illumination or daytime conditions with higher illumination. The daytime condition visual display was bright, with textured grass on either side of the runway. Simulated down the middle of the runway were 36-m-long hashmarks with a 24-m gap between them (see Figure 2). The night-timecondition visual displayed runway lights at the side of the runway $120 \mathrm{~m}$ apart and lights down the middle of the runway positioned not more than $15 \mathrm{~m}$ apart (see Figure 3). To signal target distances, two 1.8-m (six-foot) tall men were shown holding a red-and-white striped ribbon across the runway at specified target distances. The target, the ribbon and the men were illuminated for night-time scenes. 


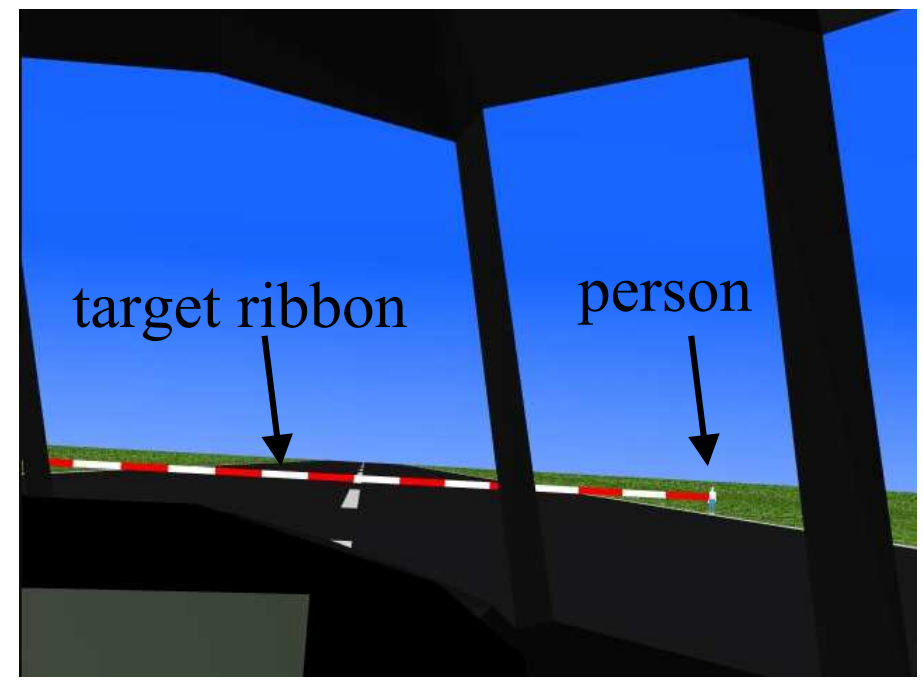

Fig. 2. Daytime display condition showing two six-foot men holding a striped-ribbon target across the runway.



Fig. 3. Night-time display condition showing two six-foot men holding a striped-ribbon target across the runway.

\section{Tilt profile}

Tilting the simulator cockpit generated non-visual cues. Subjects' heads were not restrained; subjects were instructed to hold their head steady so their head and thus the HMD had about the same tilt as the platform. The HMD was equipped with a tracking system attached to the cockpit; the movements of the cockpit had no effect on the visual display. The tilt angle selected simulated acceleration expressed as sine $(\theta) g$ (with $g$ being the universal gravi- 
tational constant). Introducing tilts at maximum acceleration of $0.5^{\circ} / \mathrm{s}^{2}$ avoided signals from the subject's semicircular canals. Figure 4 shows a sample tilt profile. Figure 5 shows how tilt simulated linear acceleration.

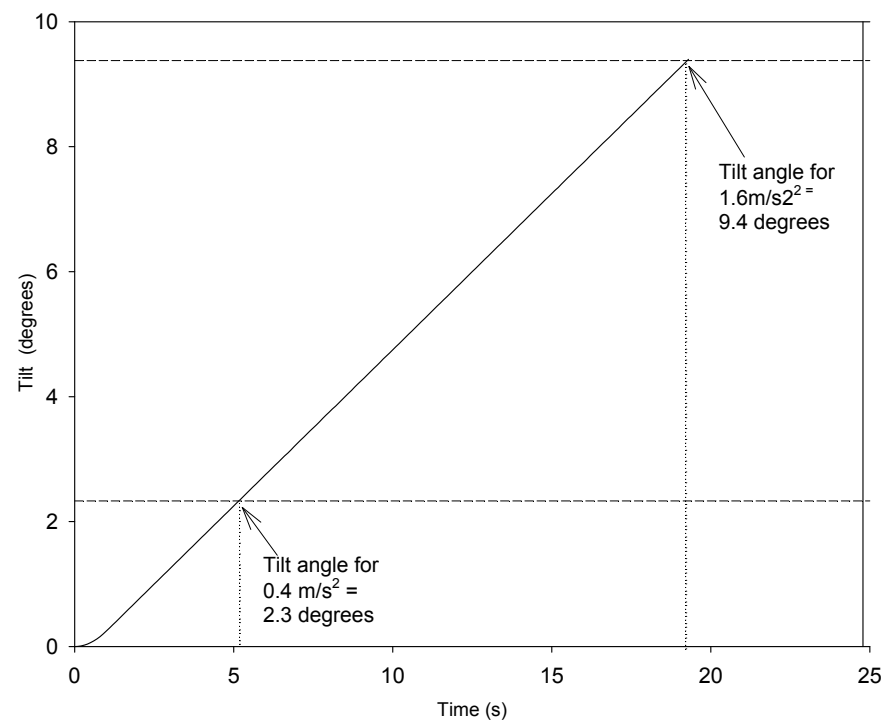

Fig. 4. The motion profile of the tilt used in this experiment.

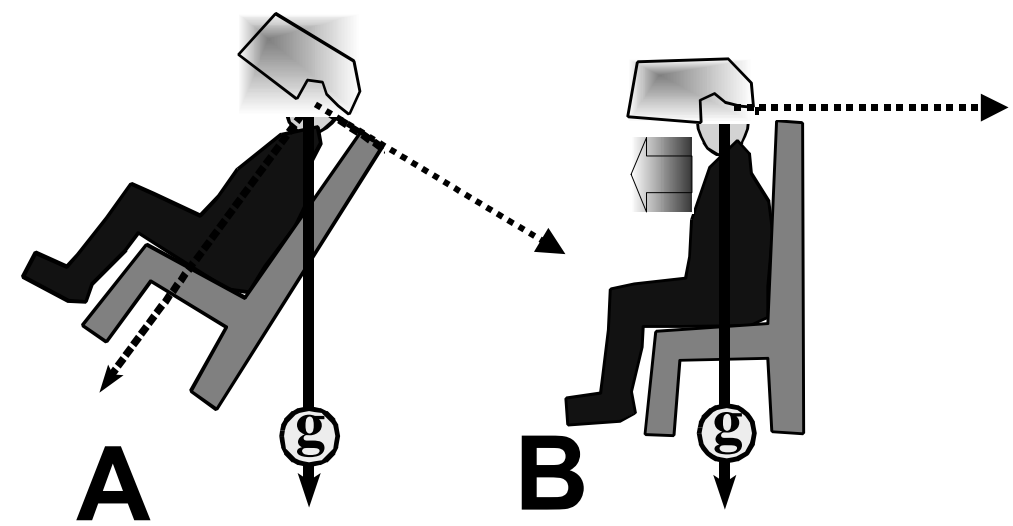

Fig. 5. An illustration of how tilt simulated linear acceleration. 
During the first second of movement the platform moved through the first quarter of a degree at $\theta=1 / 2 \alpha \mathrm{t}^{2}$ where $\alpha$ is $0.5^{\circ} / \mathrm{s}^{2}$. Following the first second the platform continued tilting at $\omega^{*} t+\theta^{*} t=1$ where $\omega$ is $0.5^{\circ} / \mathrm{s}$ until the intended tilt was reached. This tilt was held until the subject pressed the button, at which time the platform returned to its starting orientation.

When the subject was tilted as shown in Figure 5A, gravity separated into two vectors, one lying in the horizontal plane of the head and the other aligning with the body axis. As shown in Figure 5B, the direction of the horizontal-plane component was the same as the acceleration caused by a horizontal acceleration. Subjects viewed a virtual-reality display throughout the tilt.

\section{Procedure}

Prior to strapping into the cockpit, subjects were told they would be judging their simulated motion in a flight simulator by pressing a button indicating when they perceived they had moved through a specified target distance. During the experiment subjects pressed a button mounted on the control stick; they were then presented with either the daytime or nighttime runway on the visual display. The constant sound of an idling Hercules aircraft, playing over loudspeakers, masked the sounds from tilting the platform. Subjects pressed the button again when ready to start the trial. A target then appeared at some distance along the runway depicting two simulated six-foot men holding a striped ribbon at a height of $1.8 \mathrm{~m}$ across the runway, as seen in Figures 2 and 3. Subjects were instructed to move their head, obtaining parallax information to help in determining the distance to the target. Subjects were also instructed to check the position of the reference line on the floor of the cockpit. They were to align this reference line with the position of the target. When ready, subjects pressed the button again and held their heads steady while the target (along with the men) disappeared; the simulated plane began moving down the simulated runway at a constant acceleration using either visual cues (via the HMD) or a combination of visual- and physical-motion cues. For conditions with an associated platform tilt, the tilt was introduced as the visual simulation of motion began. Subjects indicated when the aircraft had moved in the simulated environment to a position where the reference line on the floor of the cockpit was over the point marked by the ribbon by pressing the button one more time. Afterwards the screen went blank, and the platform returned slowly $\left(0.5^{\circ} / \mathrm{s}\right.$, avoiding activating the canals) to its initial orientation. For non-tilt conditions, a blank period of the same duration it would take the platform to return to its initial orientation was used. Subjects indicated they were ready for a new trial by pressing the button once again.

\section{Conditions}

Targets were shown at 9 distances: 10, 20, 30, 40, 50, 60, 70, 80 and $90 \mathrm{~m}$ for each condition. The tilt condition had three levels; no tilt and tilt at either $2.3^{\circ}$ or $9.4^{\circ}$, corresponding to 0.4 $\mathrm{m} / \mathrm{s}^{2}$ and $1.6 \mathrm{~m} / \mathrm{s}^{2}$. (See Figure 4 for the tilt profile.) The acceleration condition had two levels, constant acceleration of either $0.4 \mathrm{~m} / \mathrm{s}^{2}$ or $1.6 \mathrm{~m} / \mathrm{s}^{2}$; this was accompanied by a tilt or by no tilt. The visual condition had two levels, day and night. Table 1 shows the full set of experimental conditions. The experiment was a $2 \times 2 \times 2$, complete within subjects design with each subject receiving 72 different trials in one of two random orders (counterbalanced). 


\begin{tabular}{|l|l|l|l|}
\hline $\begin{array}{c}\text { ACCELERATION } \\
\text { CONDITION }\end{array}$ & $\begin{array}{c}\text { VISUAL } \\
\text { CONDITION }\end{array}$ & $\begin{array}{c}\text { TILT } \\
\text { CONDITION }\end{array}$ & $\begin{array}{c}\text { PRESENTED DISTANCES FOR } \\
\text { EACH CONDITION (IN METERS) }\end{array}$ \\
\hline $0.4 \mathrm{~m} / \mathrm{s}^{2}$ & Day & $2.3^{\circ}$ & $10,20,30,40,50,60,70,80,90$ \\
$0.4 \mathrm{~m} / \mathrm{s}^{2}$ & Day & $0^{\circ}$ & $10,20,30,40,50,60,70,80,90$ \\
$0.4 \mathrm{~m} / \mathrm{s}^{2}$ & Night & $2.3^{\circ}$ & $10,20,30,40,50,60,70,80,90$ \\
$0.4 \mathrm{~m} / \mathrm{s}^{2}$ & Night & $0^{\circ}$ & $10,20,30,40,50,60,70,80,90$ \\
$1.6 \mathrm{~m} / \mathrm{s}^{2}$ & Day & $9.4^{\circ}$ & $10,20,30,40,50,60,70,80,90$ \\
$1.6 \mathrm{~m} / \mathrm{s}^{2}$ & Day & $0^{\circ}$ & $10,20,30,40,50,60,70,80,90$ \\
$1.6 \mathrm{~m} / \mathrm{s}^{2}$ & Night & $9.4^{\circ}$ & $10,20,30,40,50,60,70,80,90$ \\
$1.6 \mathrm{~m} / \mathrm{s}^{2}$ & Night & $0^{\circ}$ & $10,20,30,40,50,60,70,80,90$ \\
\hline
\end{tabular}

Table 1. Experimental conditions of study.

\section{Simulator sickness questionnaire}

Using the simulator sickness questionnaire (SSQ) of Kennedy et al. [8], we assessed comfort levels and unwanted side effects associated with combining visual and real movement cues. Subjects completed this questionnaire before and after the experiment. A copy of this questionnaire is included as Annex A.

\section{Data analysis}

The distance where each subject pressed the button, called the response distance. We call the ratio of the stimulus to response distance the perceptual gain, see Harris et al. [2]. Obtaining a perceptual gain of unity occurs when a subject presses the button at the exact position of the target on the runway. Pressing the button before reaching the target corresponds to a perceptual gain greater than one. Reliable comparisons between different conditions were possible because the matching task used here incorporated the same target distances. Reducing the data to a set of perceptual gains for each subject and each condition, a total of 864 judgements were collected from 12 subjects.

Response distance was regressed on stimulus distance for the six conditions (tilt vs. no tilt, day vs. night, low acceleration vs. high acceleration). The mean $r^{2}$ for each subject's slope is shown in Figure 6. Subjects with a mean $r^{2}$ not meeting or exceeding a value of 0.70 were removed from further analysis. Figure $7 \mathrm{~B}$ shows the distribution between the accepted data compared with the distribution of the rejected data. Three subjects (B.K., P.J. and A.G.) did not meet this criterion and their data were discarded from further analysis. 


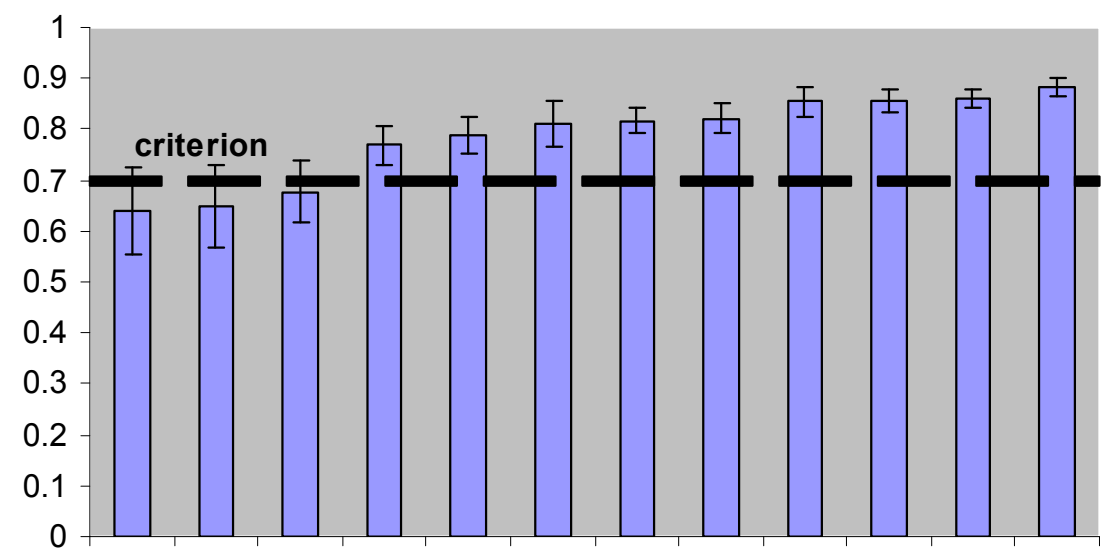

B.K. A.G. P.J. A.H. M.L. K.D. R.D. N.M. S.S. M.S. E.G. J.G.

Fig. 6. A graphic illustration of mean $r^{2}$ values for all twelve subjects.

Perceptual gain is defined as the slope of stimulus to response distance, as seen in Figure 7A. Perceptual gain is defined as the reciprocal of the slope (dashed line). Figure 7B compares the distribution of rejected response data (i.e. subjects with average $r^{2}$ less than 0.70) with the distribution of accepted data.

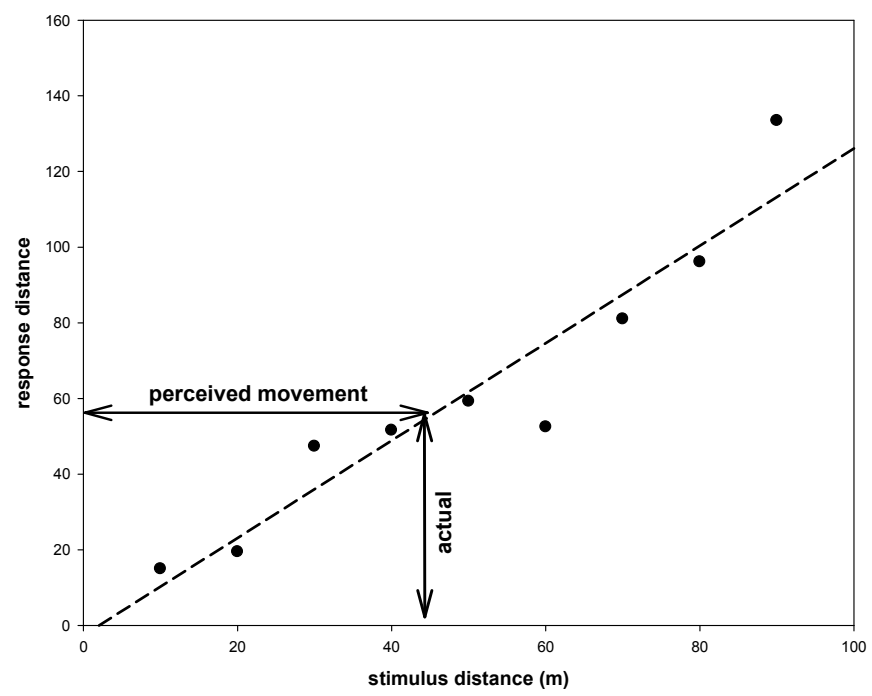

Fig. 7. A graphic example of perceptual gain. Perceptual gain is defined as the slope of stimulus to response where a gain greater than unity (1) indicates an overestimates of one's motion. 


\section{Results}

A total of 72 perceptual gains (slope : stimulus / response) were calculated from the nine subjects who passed the $r^{2}$ criterion. These are given in Table 2. This set of 72 responses was collapsed across various parameters to allow us to make statements concerning the influence of each of the various parameters. A repeated measures analysis of variance (ANOVA) was performed on the data set for the physical motion (tilt), illumination (day vs. night) and acceleration factors.

\begin{tabular}{|l|l|l|l|l|l|l|l|l|l|l|l|}
\hline $\begin{array}{l}\text { VSUAL } \\
\text { CONDITION }\end{array}$ & $\begin{array}{c}\text { ACCELE } \\
\text { RATION }\end{array}$ & TLLT & K.D. & M.L & R.D. & ES. & J.G. & M.S. & A.H. & N.M. & S.S. \\
\hline Day & 0.4 & tilt & 0.66 & 0.55 & 1.10 & 0.83 & 0.75 & 1.28 & 0.55 & 1.01 & 0.61 \\
\hline Day & 0.4 & no tilt & 0.74 & 0.52 & 0.83 & 0.70 & 0.75 & 1.05 & 0.59 & 0.99 & 0.73 \\
\hline Day & 1.6 & tilt & 0.90 & 1.08 & 1.31 & 0.85 & 0.96 & 1.20 & 0.71 & 1.50 & 0.64 \\
\hline Day & 1.6 & no tilt & 0.68 & 0.62 & 1.03 & 0.72 & 0.66 & 1.11 & 0.67 & 1.16 & 0.51 \\
\hline Night & 0.4 & tilt & 1.05 & 0.98 & 1.10 & 1.14 & 1.01 & 1.27 & 0.69 & 1.70 & 0.56 \\
\hline Night & 0.4 & no tilt & 0.92 & 1.05 & 1.18 & 1.30 & 0.84 & 1.21 & 1.22 & 1.97 & 0.77 \\
\hline Night & 1.6 & tilt & 1.30 & 0.94 & 1.23 & 1.27 & 1.27 & 1.11 & 0.61 & 1.70 & 0.64 \\
\hline Night & 1.6 & no tilt & 0.88 & 0.76 & 1.11 & 1.24 & 0.92 & 1.59 & 1.10 & 1.50 & 0.81 \\
\hline
\end{tabular}

Table 2. Summary of perceptual gains for each subject under each condition.

As Figure 8 illustrates, when tilt was applied the p response was 1.00 with a standard error (SE) of \pm 0.05 . When no tilt was applied the $p$ response was $0.96 \pm 0.05 \mathrm{SE}$. In daylight conditions, no tilt produced a lower perceptual gain response $(0.96 \pm 0.05 \mathrm{SE})$ than tilt $(1.00 \pm 0.05$ $\mathrm{SE})$, but in night-time conditions tilt had no effect, $\underline{\mathrm{F}}(1,8)=5.47, \underline{\mathrm{p}}<.05$, Tukey-Kramer, $\underline{\mathrm{p}}<$ .05 . There was no significant main effect of tilt, $\underline{F}(1,8)=0.86, \underline{p}>0.5$ or other significant interactions with tilt. 


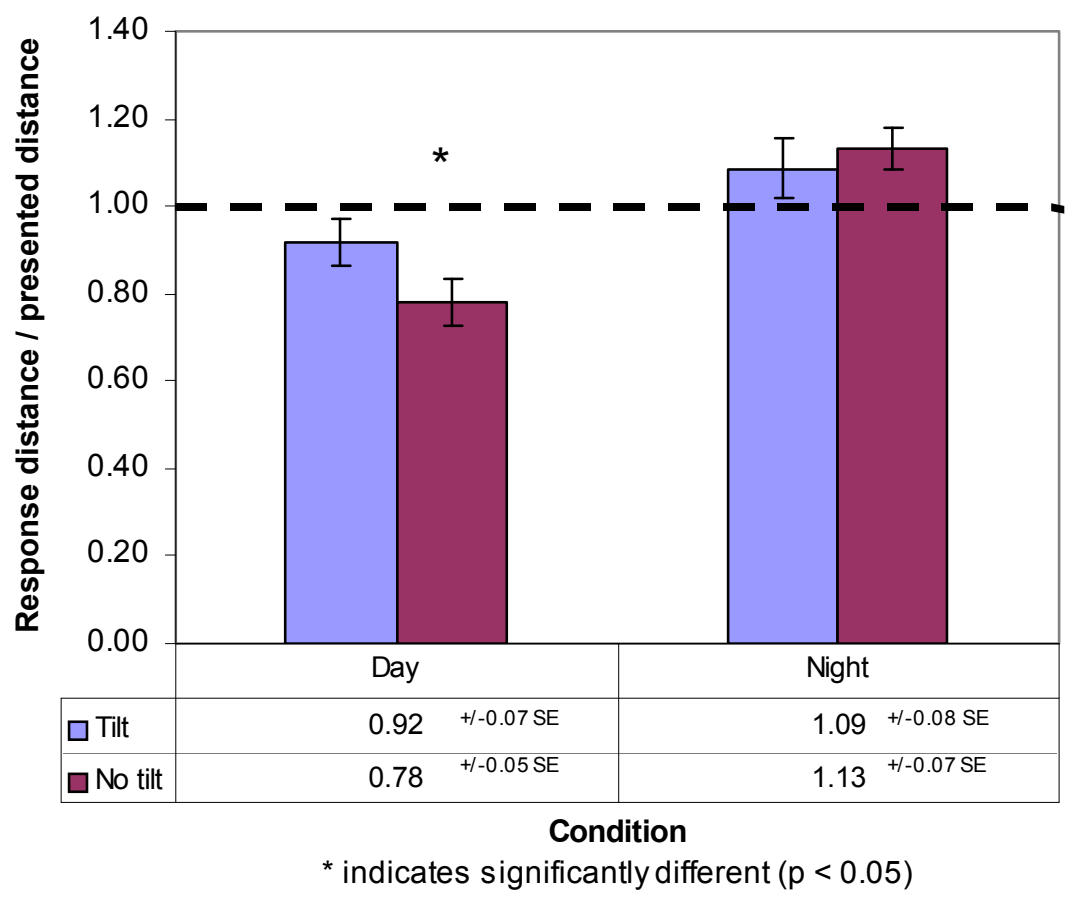

Fig. 8. A graphic summary of perceptual gains obtained in tilt and no-tilt conditions.

To determine any influence of target distance, the log ratio of the difference between response distance and stimulus distance was computed for each target distance (see Figure 9). A Hotelling-t-test was conducted to determine whether these ratios were different from zero.

This Hotelling test accounts for the many t-tests performed on the same data set. Statistically, $\log$ ratios of daytime conditions were different from zero for both $0.4 \mathrm{~m} / \mathrm{s}^{2}(t(81)=$ $4.20, \underline{\mathrm{p}}<.01)$ and $1.6 \mathrm{~m} / \mathrm{s}^{2}(t(81)=8.59, \underline{\mathrm{p}}<.01)$. However, night-time conditions were not statistically different from zero except for targets from 10 to $20 \mathrm{~m}$ for the $1.6 \mathrm{~m} / \mathrm{s}^{2}$ condition $(t(18)=3.60, \mathrm{p}<.001)$. For night-time conditions the log ratios were statistically different from zero for all targets with a $0.4 \mathrm{~m} / \mathrm{s}^{2}$ profile $(t(81)=0.41, \mathrm{NS})$ and for targets from 30 to $90 \mathrm{~m}$ with an $1.6 \mathrm{~m} / \mathrm{s}^{2}$ profile $(t(63)=1.77$, NS). The difference between the daytime and night-time curves differed significantly for targets above $30 \mathrm{~m}(t(63)=3.55, \underline{p}<.05)$. 


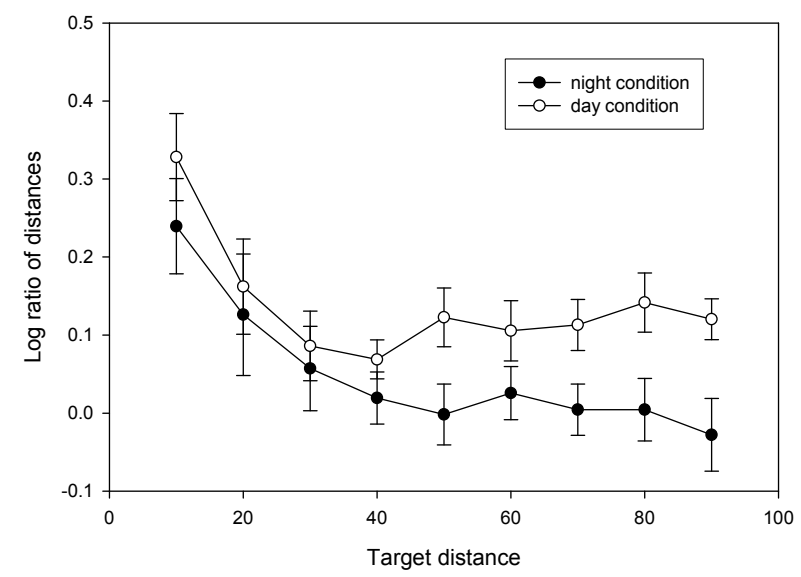

Fig. 9. An illustration of the log ratios of distance estimates with SE bars shown as a function of target distance.

Illumination had a significant effect (1.11 night-time vs. 0.85 daytime, $\underline{F}(1,8)=45.19$, $\underline{p}<$ 0.01). Unlike the interaction of illumination and tilt, interaction between illumination and acceleration $(\underline{F}(1,8)=1.64, \underline{p}>.05)$ was insignificant.

Mean perceptual gain responses for the low acceleration $\left(0.4 \mathrm{~m} / \mathrm{s}^{2}\right)$ were $0.95 \pm 0.06$, while the high acceleration $\left(1.6 \mathrm{~m} / \mathrm{s}^{2}\right)$ produced a mean perceptual gain response of $1.01 \pm 0.05$; these differed significantly $(\underline{F}(1,8)=13.62, \underline{p}<0.01)$.

\section{Simulator sickness}

Figure 10 compares SSQ scores (see Annex A for weighted calculation methodology) for each subject before and after the experiments. No significant change was found between pre-simulation and post-simulation scores for any of the three sub-scores (nausea, oculomotor and disorientation) measured. The average values both before (5.0) and after (12.4) were well below the minimal discomfort level of 50 suggested by Kennedy et al. [8]. 


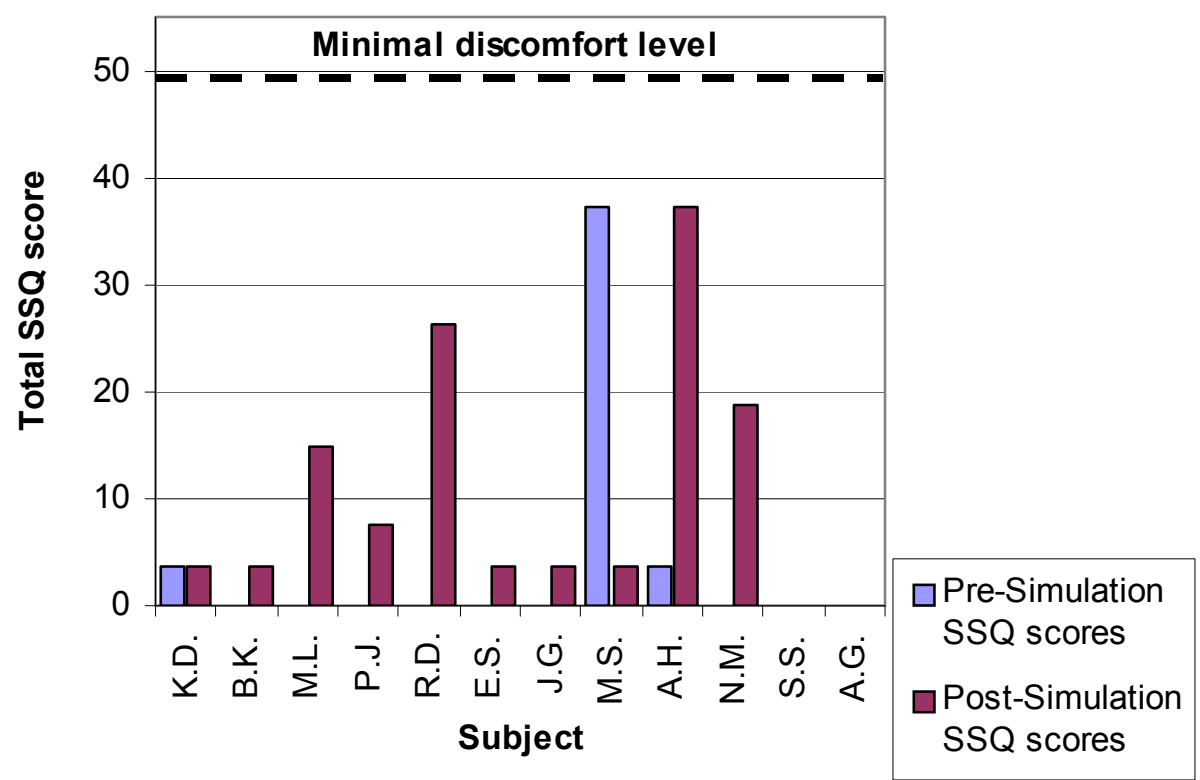

Fig. 10. A graphic summary of pre- and post-motion SSQ scores. Dashed line indicates minimal discomfort level. A response of zero is represented by a missing bar.

\section{Discussion and conclusion}

This study has examined a continuum of sensation from full visual to full physical motion stimuli. From fully illuminated day-like conditions to dimly light night-like visual conditions to complete darkness with only physical motion to simulate the movement of the subject, the experiments presented here offer some interesting results. Simulating day or night conditions affects perceived distance travelled differently during passive translation in a taxiing simulator. Subjects estimate that they have moved further under simulated nighttime conditions. Reducing illumination to night-time lighting conditions may reduce the influence of visual cues; that is, they increase dependence on non-visual cues. When visual cues are absent, non-visual cues are heavily weighted by the nervous system. Harris et al. [2] showed that with no light at all, passive physical self-motion was perceived as considerably greater than actual motion (up to three times the perceived visual distance).

Contrast may have played a significant factor in determining the results during night-like simulated conditions. The high contracts of runway lights contrasting starkly with a dim background create high contrast patterns during night simulations. In Snowden et al. [9], observers underestimated their speed when moving in driving simulations under fog conditions. These results are compatible with Thompson's [10] results, which indicated that low contrast induces lower judgments of visual motion. In the study presented here, subjects 
overestimate their motion, indicating their perception is perhaps dominated by physical motion cues.

By tilting at low rates of rotation, gravity stimulates the otolith's utricular macula without activating the canal system. The otolithic stimulation is in the direction of, and at a magnitude compatible with, the simultaneous visually-simulated movement. The present study compares conditions with and without tilt to visual motion alone as a control, finding perceptual gain responses closer to 1 when tilt was added. Harris et al. [2] found overestimates (response distance $1 / 3$ of the stimulus distance) of self-motion in the presence of linear motion only, or with visually-simulated hallway movement (response distance of $1 / 2$ of stimulus distance). Perhaps the disparity between Harris et al. [2] and the current findings is due to the simulated translation using tilt rather than the real translation (using a sled) experienced by the Harris et al. [2] subjects. Therefore, although tilt is not physically distinguishable from linear acceleration, perceptually tilt does not match the real amplitude of linear translation.

Although there is no overall effect of tilt on motion in the present study, there is an interaction between simulated illumination and tilt. Under night-time conditions, perceptual gain was higher (1.02 night vs. 0.92 day), as might be expected if the nervous system more readily relies on physical motion. Oddly enough, perceptual gain responses are higher without tilt (1.13 no tilt vs. 1.09) under night conditions; this may be reflective of the speeding up of the perception of self-motion as found by both Snowden et al. [9] and Thompson [10]. During simulated day conditions the perceptual gain is relatively low (0.78); however, accuracy improves substantially (from 0.78 to 0.92 ) with simultaneous tilt. Therefore, tilt may increase accuracy irrespective of simulated illumination.

The consequences of the tilt-illumination interaction may provide insight into the somatogravic illusion. The somatogravic illusion (illusion of pitch caused by forward acceleration) occurs under night-time flight conditions; see Gillingham and Wolfe [11]. The same overestimation of tilt, and therefore self-motion, occurs under night-time simulation conditions in the current study.

While considering these results, one must also consider the general mismatch between the visual and physical motions of the simulator. Due to limitations of flight simulators, visual motion normally begins before the platform has reached its maximum tilt angle. The low rate of tilt used in these experiments means in certain conditions (shorter-range targets, higher-target accelerations and various combinations) the visual simulated self-motion is not initially matched with enough tilt to be perceived as veridical. However, apparently this mismatch does not hinder performance (average perceptual gain responses were close to 1) and because linear vection has been known to delay onset from 8 to $15 \mathrm{~s}$, it is doubtful the mismatch between vision and physical motion created any misperception, see Berthoz et al. [12].

Pilots taxiing along runways need to know be reasonably accurate at determining their current position relative to other objects as well as the taxiway. Under good lighting conditions, in modern airports, this localization is usually very accurate. When airport systems are faulty or absent, the task of localization falls on the pilot. How well can a taxiing pilot discern positions and distances on the runway?

This experiment suggests users under passive simulation conditions judge their motion differently during night-time and daytime scenarios. Applying the results to pilots who are in active control of real aircraft, we expect errors in taxiing performance. Specifically, if pilots 
perceive they have travelled further at night than they have, they will tend to stop short. If simulator manufacturers continue using equal amounts of tilt and visual motion for both day and night conditions, errors of self-motion during training may occur, carrying over into real-world taxiing performance. Training pilots to overestimate their motion with a night-time display may transfer this overestimation into real-world taxing performance, leading pilots to stop short or turn too early. Similarly, underestimating self-motion during daytime viewing may result in the aircraft colliding with other vehicles, equipment or buildings.

To correct these errors, research is required to establish the correct tilt-to-vision ratio (tiltgain) for both night-time and daytime viewing conditions, as they would be in the field. Simulator training can match field training once the correct tilt-gain is established. Until simulation training matches field training, participants should be trained to rely on their instruments (odometer) to judge their self-motion; although, it is more advantageous to have pilots looking up and using out-the-window information during such manoeuvres. These conclusions are based on the assumption that this artificial means of simulating translation through tilt does not correspond to the perception of self-motion during real translations of the observer.

The high perceptual gains found during night-time taxiing are consistent with earlier results; those results indicate an overestimation of motion as the quality or availability of visual cues are reduced, see Harris et al. [2]. Before tackling the problem of tilt-gain, simulation designers must consider the level of illumination available; simulating forward acceleration with pitch is less effective for simulated night conditions than for simulated day conditions. One new approach may be to implement a different strategy incorporating level of illumination as a parameter.

Simulator designers should consider how the results found here (maximum perceptual gain of 1.1) differ from those found in the literature for real linear translation. For example, Harris et al. [2] found perceptual gains of approximately 2.07 when physical motion accompanied visual motion. Simulations using tilt, while producing near veridical gains, may need to add a tilt-gain (greater pitch angle than visual motion requires) when accurately simulating real-world perceptions of motion. Groen and Hosman [5] found that subjects set tilt-gain to 0.6 (roughly equivalent to what we would call a perceptual gain of 1.4), indicating they perceived a tilt-gain of 1 to be too high. The Groen and Hosman [5] study used higher acceleration values $\left(3.34 \mathrm{~m} / \mathrm{s}^{2}\right)$ compared with the values used here (maximum $\left.1.4 \mathrm{~m} / \mathrm{s}^{2}\right)$, \& different rate of tilt, possibly accounting for the difference in perceptual gain. The most veridical simulation matches perceptual values found in simulation studies with those found in real linear-translation studies. A study is needed to determine the correct ratio of tilt-gain and tilt-rate (the rate at which the tilt occurs) to visual motion. This study highlights that this ratio likely depends on the amount of illumination in the visual display.

New questions are raised by the presented results. Do these results extend to well-trained pilots? Do these results extend beyond simulation to taxiing in an aircraft? Do the results extend to situations where the operator actively controls the aircraft or simulator? A trade-off between tilt and acceleration is used to simulate forward motion in the design of contemporary flight simulators. This trade-off is not an isolated phenomenon or the representation of a closed system; perceiving distance travelled is affected by other factors. Importantly, this perception is affected by illumination level, i.e., whether a day scene or a night scene is depicted. 


\section{References}

Transport Canada (2003). Transportation in Canada, annual report: TP 13198E, Minister of Public Works and Government Services, Canada. pp. 1-106.

Harris, L. R., Jenkin, M., and Zikovitz, D. C. (2000). Visual and non-visual cues in the perception of linear self-motion. Experimental Brain Research, 135(1), 12-21.

Fotos, C. P. (1990). Northwest 727, DC-9 crash. Aviation Week \& Space Technology, December 10, 1990, 133 (24), p 33, Washington.

Vos, A.P. de, Hoekstra, W., and Pieterse, M.T.J. (1998). The effect of acceleration. The effect of acceleration cueing on braking behaviour in a driving simulator. Report tm-98a066 TNO-Human Factors, Soesterberg, the Netherlands. pp. 1-21.

Groen, E. and Hosman, R. (2001). Evaluation of perceived motion during a simulated takeoff. Journal of Aircraft, 38, 600-606.

Einstein, A. (1922). The meaning of relativity: Princeton, NJ: Princeton University.

Benson, A. J., Hutt, E. C., and Brown, S. F. (1989). Thresholds for the perception of whole body angular movement about a vertical axis. Aviation, Space, and Environmental Medicine, 60, 205-213.

Kennedy, R., Lane, N., Berbaum, K., and Lilienthal, M. (1993). Simulator sickness questionnaire: an enhanced method for quantifying simulator sickness. International Journal of Aviation Psychology, 3(3), 203-220.

Snowden, R., Stimpson, N., and Ruddle, R. (1998). Speed perception fogs up as visibility drops. Nature, 450, 392.

Thompson, P. (1982). Perceived rate of movement depends on contrast. Vision Research, 22, 377-380.

Gillingham, K.K. and Wolfe, J.W. (1985). Spatial orientation in flight. In Dehart R.L., ed. Fundamentals of aerospace medicine, pp. 299-381. Philadelphia: Lea and Febiger.

Berthoz, A., Pavard, B., and Young, L. R. (1975). Perception of linear horizontal self-motion induced by peripheral vision (linear vection). Basic characteristic and visualvestibular interactions. Exp. Brain Res., 23, 471-489.

\section{Annex A: The simulator sickness questionnaire}

The SSQ from Kennedy et al., [8] is a self-report form consisting of 17 symptoms the participant rates on a four-point scale. Quantifying the symptoms and their strength if present, the SSQ is based on three components: nausea, oculomotor problems and disorientation. Combining these scores produces a total SSQ score. Participants report the degree to which they experience each of the symptoms as 0 for none, 1 for slight, 2 for moderate and 3 for severe. For each component, the column's reported value is multiplied by the weight for that column and then summed down the columns. The total SSQ score is obtained by adding the scale scores across the three columns and multiplying by 3.74 . Weighted scale scores for individual columns are calculated by multiplying the nausea subscale score by 9.54 , the oculomotor subscale by 7.58 and the disorientation subscale by 13.92 . 


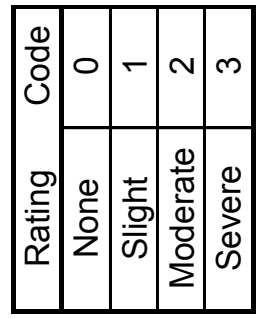

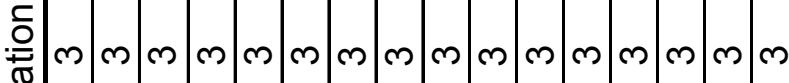

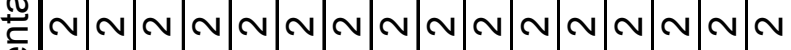

$\begin{array}{ccccccccccccccccc}\frac{\mathscr{O}}{0} & 0 & 0 & 0 & 0 & 0 & 0 & 0 & 0 & 0 & 0 & 0 & 0 & 0 & 0 & 0 & 0\end{array}$

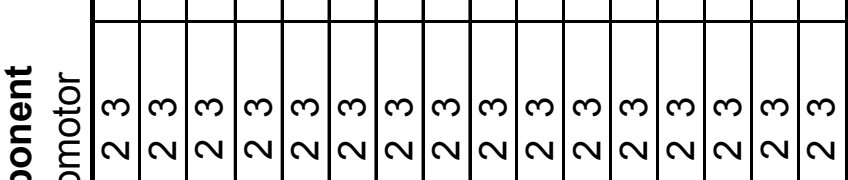

을 을

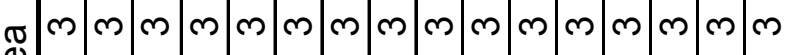

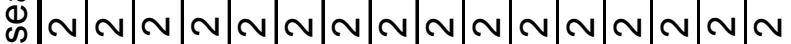

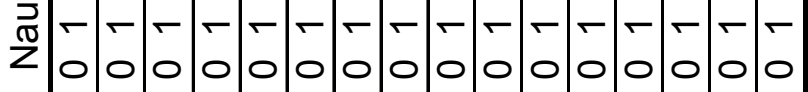

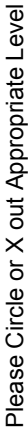

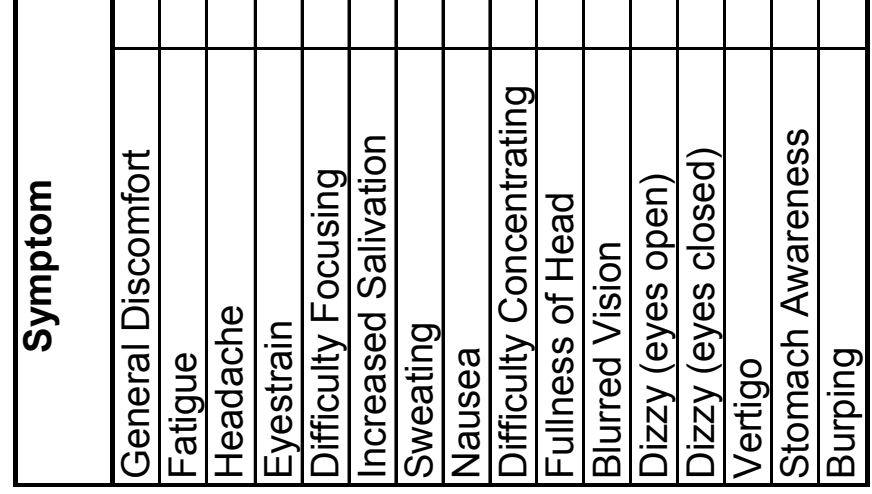




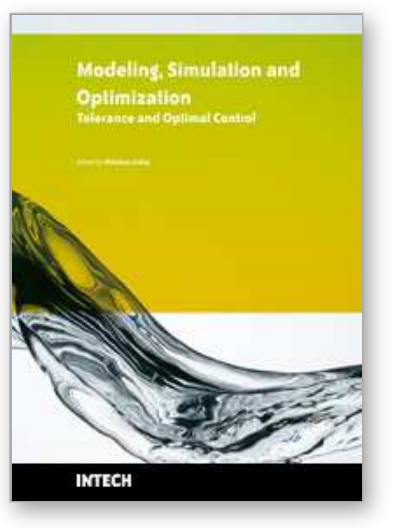

\section{Modeling Simulation and Optimization - Tolerance and Optimal Control}

Edited by Shkelzen Cakaj

ISBN 978-953-307-056-8

Hard cover, 304 pages

Publisher InTech

Published online 01, April, 2010

Published in print edition April, 2010

Parametric representation of shapes, mechanical components modeling with 3D visualization techniques using object oriented programming, the well known golden ratio application on vertical and horizontal displacement investigations of the ground surface, spatial modeling and simulating of dynamic continuous fluid flow process, simulation model for waste-water treatment, an interaction of tilt and illumination conditions at flight simulation and errors in taxiing performance, plant layout optimal plot plan, atmospheric modeling for weather prediction, a stochastic search method that explores the solutions for hill climbing process, cellular automata simulations, thyristor switching characteristics simulation, and simulation framework toward bandwidth quantization and measurement, are all topics with appropriate results from different research backgrounds focused on tolerance analysis and optimal control provided in this book.

\section{How to reference}

In order to correctly reference this scholarly work, feel free to copy and paste the following:

Daniel C. Zikovitz, Keith K. Niall, Laurence R. Harris and Michael Jenkin (2010). Simulated Day and Night Effects on Perceived Motion in an Aircraft Taxiing Simulator, Modeling Simulation and Optimization - Tolerance and Optimal Control, Shkelzen Cakaj (Ed.), ISBN: 978-953-307-056-8, InTech, Available from: http://www.intechopen.com/books/modeling-simulation-and-optimization-tolerance-and-optimalcontrol/simulated-day-and-night-effects-on-perceived-motion-in-an-aircraft-taxiing-simulator

\section{INTECH}

open science | open minds

\author{
InTech Europe \\ University Campus STeP Ri \\ Slavka Krautzeka 83/A \\ 51000 Rijeka, Croatia \\ Phone: +385 (51) 770447 \\ Fax: +385 (51) 686166 \\ www.intechopen.com
}

\author{
InTech China \\ Unit 405, Office Block, Hotel Equatorial Shanghai \\ No.65, Yan An Road (West), Shanghai, 200040, China \\ 中国上海市延安西路65号上海国际贵都大饭店办公楼405单元 \\ Phone: +86-21-62489820 \\ Fax: +86-21-62489821
}


(C) 2010 The Author(s). Licensee IntechOpen. This chapter is distributed under the terms of the Creative Commons Attribution-NonCommercialShareAlike-3.0 License, which permits use, distribution and reproduction for non-commercial purposes, provided the original is properly cited and derivative works building on this content are distributed under the same license. 